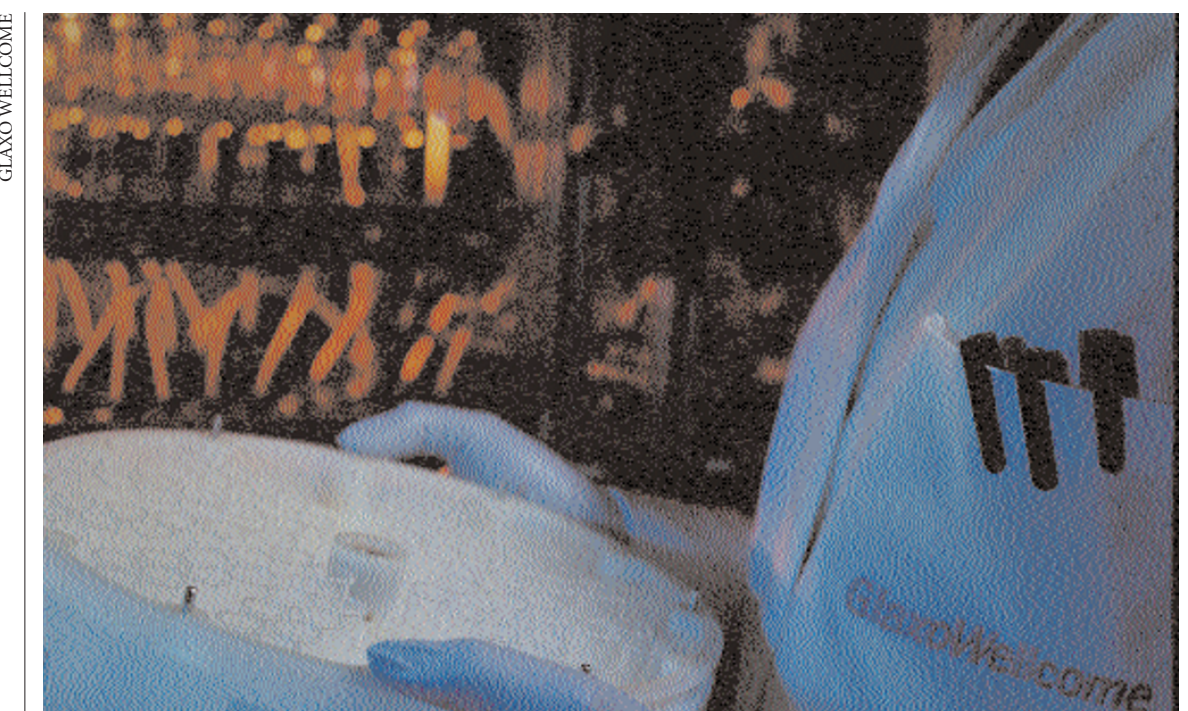

Profit potential: proteomics could open the door to major commercial gains.

eters determine the mass of the protein or subunits of the proteins in a complex. If the proportion of the protein's constituent amino acids is known, computers can then take over the task of identifying the protein. Software then looks for a DNA sequence that would code for a protein made up of the known amino-acid composition. Finally, the mass spectrometer determines the protein's exact mass.

Compared with their peers of two decades ago, researchers applying these techniques to drug discovery are off to a flying start in the effort to identify protein function. Even if the databases they search are not annotated with function, the identified proteins are those taken from diseased tissue. So there is at least a correlation pointing to the protein's potential application.

There are still many weaknesses in the technologies used for proteomics (see Nature 402, 715-720; 1999), and the subsequent job of identifying the exact role of the proteins in the cell remains a complex biological problem. But current technology is far enough advanced to meet the aims of Oxford GlycoSciences, according to Burns. The company can analyse 1,000 proteins per month and is spending the money raised in February on further developing its protein identification effort.

"We have optimized the first generation of the technology," says Burns. "It is cumbersome - like a Model-T Ford - but it gets us from A to B." That destination is the world's patent offices. Oxford GlycoSciences' strategy is driven by the perception that there is a single window of opportunity - now when the DNA sequences and gene maps currently being completed can be exploited to identify proteins. "It is," says Burns, "two minutes to twelve and counting."

The aim of this frenetic activity is that in future years these patents will, so to speak, pay dividends. As knowledge of the proteins and protein complexes in the body involved in disease deepens, those owning protein and/or gene patents could find themselves in a powerful commercial position.

\section{Amino activity}

Broadly speaking, proteomics can be divided into two conceptual approaches, argues Walter Blackstock, from Glaxo Wellcome Research and Development. These are expression proteomics - comparing the complement of proteins expressed by healthy and diseased tissue - and cell-map proteomics - the study of protein-protein interactions. Both routes rely on a suite of technologies that separate and identify proteins associated with disease, and both have the aim of improving the selection of the optimum target for drug development.

Industry has led academia in the field of proteomics, both in Europe and the United
States, according to Alf Game, head of the genetics and biochemistry branch of Britain's Biotechnology and Biological Sciences Research Council (BBSRC). Nevertheless, large pharmaceutical companies were not immediately impressed by the technology. Initially, spin-offs from universities led the way.

"There was a lot of hype," says Blackstock. "You have to remember that proteomics is not the only approach to drug discovery and target validation. We were weighing a non-proven technology against proven methods."

But the caution is fading. "Big pharma is now switching to proteomics," says Blackstock, who heads the cell-map proteomics unit at Glaxo Wellcome. The unit was formed 14 months ago after 12 months spent studying the field informally.

Proteomics is such a large and complex field that there is still room for newcomers to the industrial scene. It is the proteins themselves that make the field so challenging and unpredictable. Although the human genome codes for about 100,000 genes, the variety of proteins in the body is many times greater. This is because genes essentially code for an amino-acid sequence.

Once expressed, many things happen to these proteins. For example, functional groups are added or the protein is cleaved. Proteomics aims to identify proteins in vivo, where such post-translational changes might mean that there are millions to be detected. Furthermore, the state of proteins changes with time. Unlike genomics, which in essence had one genome per organism on which to focus, there is, says Burns, a nearly infinite number of proteomes.

This makes finding improved proteomics tools the main goal of both industrial and academic researchers. Developing

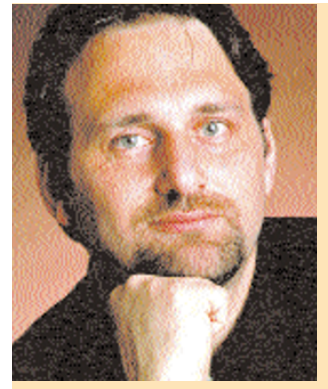
The power of prediction

Andrea Califanos, programme director of the Computational Biology Center and manager of the Functional and Structural Genomics Group at IBM's T. J. Watson Research Center in Yorktown Heights, New York, hopes that computation can make biology more predictable.

"Biology has been a descriptive science for a long time, and has lacked the abstract theoretical framework that allows you to draw complex inferences about phenomena, but this is changing," he says. "I think the union of the theoretical sciences - mathematics, physics, computer science - with biology is going to let us model, predict and, most importantly, understand the most intimate mechanisms of life."

This union - and the prediction that it will produce - may change the way in which experiments are designed. Califanos points to gene-expression analysis, where the synergy between statistics, mathematics and biology is leading to successes in relating genotype to phenotype.

Expanding this sort of success must entail more than developing a new generation of scientists with mixed degrees, he says, adding that "We need a new language". Organizations and centres such as the Center for Physics and Biology at Rockefeller University, the Institute for Advanced Studies at Princeton, and the Biophysics Institute at Johns Hopkins University, may provide one.

At IBM, rather than attracting mixed-degree people, Califanos has focused on building a team made up of an "extremely heterogeneous and eclectic group" of scientists.

P.W. 